\title{
APORTES AL MODELO DE DISEÑO ETNOGRÁFICO DE UNA EMPRESA DE AGUIRRE BAZTAN
}

Jorge Enrique Maldonado Pinto *

\footnotetext{
*Magíster en Educación, Mención Gerencia. Candidato a doctor en Educación.Profesor Departamento de Administración Universidad de Pamplona. E-mail: jmaldonadoupel@hotmail.com
} 


\section{APORTES AL MODELO DE DISEÑO ETNOGRÁFICO DE UNA EMPRESA DE AGUIRRE BAZTAN}

\section{RESUMEN}

Aguirre Baztán plantea en su libro Etnografía, en el caso que presenta el Diseño Etnográfico de una Empresa, tres clasificaciones con elementos tan importantes como la Identidad Cultural de la empresa, como las Comunicaciones Internas y Externas, el Producto, el Proceso y la Venta; queriendo aportar e enriquecer el modelo agregamos los siguientes: Estrategias, Recursos e Interacción con el Medio, además se consideró que la identidad hace parte de una clasificación más amplia como es la Cultura Organizacional.

Palabras Claves: Identidad Empresa, Comunicaciones Internas y Externas, el Producto, el Proceso y la Venta, Estrategias, Recursos, Interacción con el medio, Cultura Organizacional.

\begin{abstract}
Aguirre Baztán outlines in its book Ethnography, in the marries that presents the design ethnographic of to Company, three classifications with elements so important ace cultural the identity of the company, ace the Internal and external communications, the product, the process and the comes out; wanting to contribute and to enrich the pattern adds the following ones: strategies, resources and interaction with the means, it was also considered that the identity makes part of to wider classification ace it I the organizational culture.
\end{abstract}

Keywords: Identity Company, Internal and External Communications, the Product, the Process and the Sale, Strategies, Resources, Interaction with the means, Organizational Culture.

\section{Face IssN $^{1794-9920}$}

Recepción: Julio de 2010

Revisión: Diciembre de 2010

Aceptación: Diciembre de 2010 


\section{CULTURA ORGANIZACIONAL}

Entiéndase por Cultura Organizacional como "el conjunto de características compartidas por todos y cada uno de los miembros de la organización y que definen a la institución como tal". GONZÁLEZ Martín, OLIVARES Socorro. (1999)

Robert Vecchio la define como el "conjunto de valores y normas que existen en una organización y que son enseñados a los empleados. Esta definición de cultura organizacional incluye creencias comunes y sentimientos, comportamientos estandarizados en proceso histórico para la transmisión de valores y normas". Nos atreveríamos a conceptuar la cultura organizacional de la siguiente manera: comprende las creencias, costumbres, formas de actuar, tradiciones, sentimientos compartidos comunes que identifican a una organización en un proceso continuo de formación y de transmisión de los principios, valores, políticas y normas que deben socializarse y que forman parte de los individuos que componen una comunidad empresarial.

La cultura organizacional es aprendida, en este sentido, y también al igual que en la cultura de una sociedad, el proceso de aprendizaje se logra mediante la socialización en los individuos que forman parte de la organización. En este proceso juegan papel preponderante la comunicación, la sensibilización, además de la formalización por acciones orientadas por la alta gerencia como la capacitación. Organización que no capacita a sus miembros se le dificulta lograr sus objetivos. La cultura organizacional es dinámica. Si bien tiene una permanencia en el tiempo, es relativa. El individuo no solamente la aprende, la internaliza y la reafirma con su conducta sino que además la puede trasformar. Aparecen como factores de ese cambio aspectos del entorno social, lo que exige la capacidad de innovación y creatividad en el ser humano.

La cultura organizacional está constituida por elementos que se interaccionan y se hacen manifiestos. Estas dimensiones son:

- El concepto de liderazgo y sus diferentes estilos.

- La estructura humana de la organización con sus principios, valores, visión, misión, normas, reglas, selección, socialización, relaciones formales e informales etc.

- Las conductas manifiestas de su cultura (mitos, ritos, relatos, leyendas, creencias, costumbres, identidad, historias, biografías, religión o niveles de espiritualidad entre otros.)

- El clima organizacional.

Son muchas las condiciones que se deben dar y fundamentar para lograr una cultura organizacional y es en ese momento, en el tiempo y en el entorno, donde pueden aparecer nuevos paradigmas que podrían contribuir al mejoramiento del clima organizacional de las organizaciones. 


\section{COMUNICACIONES INTERNAS Y EXTERNAS}

Otro elemento importante del diseño etnográfico en la empresa son las comunicaciones internas y externas.

Los escritos sobre comunicación organizacional suelen tener como punto de referencia los estudios de Elton Mayo en la Western Electric de Hawthorn Illinois, en la década de 1930. Sin embargo en los escritos griegos la comunicación juega papel importante y a pesar que no se le da el sentido de ciencia, si se considera una noción implícita que hay que reconstruir. En el caso de Elton Mayo, el si aborda específicamente el tema de la comunicación como su objeto de investigación. Recurrir al origen de la comunicación a cualquiera de las anteriores referencias nos parece un poco osado de nuestra parte. Sin embargo, esto cambia radicalmente a partir de la década de los setenta, cuando surge una cantidad de libros cuyo tema central es la comunicación. Paradójicamente antes de que apareciera el interés específico por la comunicación, en la década de los 40 hubo una cantidad respetable de artículos sobre un nuevo concepto, denominado comunicación organizacional, al que podríamos definir de la siguiente forma: "disciplina cuyo objeto de estudio es la forma en que se da el fenómeno de la comunicación dentro de las organizaciones, y entre las organizaciones y su medio".

En la actualidad, creemos que se están desarrollando las siguientes líneas de investigación y de trabajo:

1. Creación de sistemas más eficaces de comunicación.

2. Desarrollo de habilidades de comunicación interpersonal y grupal.

3. Elaboración de revistas internas de comunicación.

4. Desarrollo y aplicación de nuevas tecnologías de telecomunicaciones o informática en el área de la comunicación.

Cada uno de estos aspectos presentan problemas que complican tanto su puesta en práctica como su aplicación cotidiana; usualmente estos problemas son clasificados por el nombre genérico de barreras de la comunicación. Estas se pueden clasificar en cuatro tipos: físicos, fisiológicos, semánticos y psicológicos.

Barreras físicas: se refiere a no tener los elementos adecuados para trasmitir el mensaje, por lo que éste se puede ser desvirtuado y recibirse de manera inadecuada. Por tanto, es muy importante generar en nuestras empresas los medios físicos adecuados que permitan la comunicación clara, precisa y oportuna con los trabajadores, pues de no ser así caeríamos en una barrera física que impediría la comunicación organizacional. 
Barreras fisiológicas: la percepción deficiente de cualquiera de nuestros sentidos (visión, oído, olfato, tacto) como también el acervo cultural a los que va dirigida la comunicación puede distorsionar el mensaje.

Barreras semánticas: el uso del lenguaje, los modismos, las jergas, que enriquecen o desfiguran un idioma pueden configurarse en barreras para no recibir de manera clara y objetiva el mensaje.

Con base en lo anterior se recomienda al emisor dar el mensaje con palabras simples y comunes que todos las entiendan, y redactarlas de tal manera que no pierdan su calidad, belleza y claridad.

Barreras psicológicas: recordemos que cualquier mensaje tiende a reforzar la imagen que el receptor tiene del comunicador, lo que le da un matiz muy especial al prejuicio, siendo éste un aspecto que favorece o perjudica dicha comunicación. El prejuicio puede anularse o refirmarse por la imagen que previamente el emisor revela en sus actos con gestos, posturas, formas de vestir o de arreglarse, etc., lo que genera expectativas respecto a la creencias del receptor.

Para terminar este elemento tan importante del diseño etnográfico de la empresa podríamos definir que la comunicación es un proceso mediante el cual se tramite un mensaje, donde intervienen un emisor, un medio y un receptor y que su efectividad depende de desarrollar algunas habilidades básicas para de esta forma evitar las barreras que se presentan en la comunicación. Estas habilidades básicas pueden ser: saber escuchar, conocer íntegramente al oyente, elegir el tiempo y el lugar adecuado para enviar el mensaje, organizar bien las ideas, superar las rupturas y retroalimentar la comunicación.

La comunicación puede ser formal o informal. La formal es aquella que se lleva a cabo por procedimientos concretos y la informal sigue siempre un camino natural. La comunicación informal hay que tenerla en cuenta, pues en la mayoría de las veces, bien utilizada es más efectiva que la formal. Una metodología para mejorar la comunicación es la acertividad, la cual se traduce como dar en el blanco, en acertar, ser efectivo y eficaz.

\section{PROCESO, PRODUCTO Y VENTA}

La característica de proceso, producto y venta contienen una serie de elementos como los diagramas de procesos, la innovación, la creatividad, la calidad total, el manejo adecuado de inventarios, las técnicas de almacenamiento, los procesos de reciclaje, los canales de distribución, los proveedores, el costeo de productos, los seguros, el know- 
how o conocimiento del negocio, las ferias, los cupones, los despachos oportunos o just in time, el registro de patentes, otros servicios, el benchmarking, el código de barras, la organización de la fuerza de ventas, los sistemas de trasporte, los niveles de satisfacción de clientes, el portafolio de productos, la exportación de producto y servicios, la adopción de nuevo conocimiento, la donación de productos, la ampliación y profundidad de la línea de productos, las degustaciones y las zonas o territorios de ventas. La descripción, el análisis e interpretación de los anteriores elementos dependen del tipo de empresa, del tamaño de la empresa y caracterizaciones más importantes de la empresa.

\section{ESTRATEGIA}

"Arte de coordinar las acciones y maniobras para alcanzar un objetivo", Maldonado, 2001. También podemos conceptuar como las acciones que deben realizarse para mantener y lograr los objetivos y hacer realidad los resultados esperados al establecer los proyectos estratégicos. Dentro de las estrategias se deben considerar los planes, el desarrollo humano, la actitud de cambio, el perspectivismo o considerar la realidad desde varias ópticas o puntos de vista, la intencionalidad, los nuevos desarrollos, desintermediación, competitividad, flexibilidad, la apertura económica, la rentabilidad, la participación, la anticipación, la supervivencia, la integralidad, la adaptabilidad, la globalización, la credibilidad, el mejoramiento continuo, la penetración con nuevos productos, el descreme de los mercados, la respuesta oportuna o just in time, el manejo de prioridades, las alianzas estratégicas, el crecimiento de la infraestructura, la administración del caos, la masificación de productos, la evaluación de la competencia, la creación de valor entre otros, constituyen las acciones necesarias para conseguir los resultados propuestos.

Las estrategias empresariales las podemos clasificar también de paz y de guerra, sobre todo las relacionadas con precios. Ejemplo: búsqueda de acuerdos (de paz), eliminación de competidores, (de guerra).

\section{LOS RECURSOS}

Los recursos son los elementos más importantes en las organizaciones, algunos autores consideran que sin recursos no hay empresa. Los recursos se clasifican en tecnológicos, materiales, de capital y el talento humano.

Recursos Financieros: Son los elementos monetarios propios y ajenos con que cuenta una empresa, indispensables para desarrollar su actividades. 
Entre los recursos financieros propios se pueden citar:

1. Dinero en efectivo.

2. Aportes de los socios (acciones)

3. Utilidades

4. Los recursos financieros ajenos están representados por:

5. Préstamos de acreedores y proveedores.

6. Créditos bancarios o privados.

7. Emisión de valores (bonos, cédulas, pagarés, otros)

Talento humano: Son lo más importante para la existencia de la empresa, de ellos depende el manejo y funcionamiento de los demás recursos. Los mal llamados recursos humanos o capital humano, poseen características tales como: posibilidades de desarrollo, creatividad, ideas, habilidades, imaginación, experiencias, habilidades etc., las cuales los diferencian de los demás recursos.

Según la función que desempeñen y su nivel jerárquico en que se encuentren en la organización, pueden clasificarse en:

1. Obreros. Calificados y no calificados.

2. Oficinistas. Calificados y no calificados.

3. Supervisores. Se encargan de vigilar el cumplimiento de las tareas y actividades.

4. Técnicos. Ejecutan tareas calificadas y especializadas.

5. Ejecutivos: Se encargan da las labores administrativas, de la gestión y el mando.

6. Directores. Fijan las políticas, los objetivos, las estrategias y las metas.

Recursos Tecnológicos: Aquellos que sirven como instrumentos auxiliares en la coordinación de los otros recursos:

a. Sistemas de producción, ventas, financieros, administrativos, etc.

b. Fórmulas, patentes, etc.

c. Sistemas de información tecnológica: redes, Internet, Intranet, fibra óptica.

Recursos Materiales: Son bienes tangibles y no tangibles de propiedad de la empresa:

a. Propiedades, planta y equipos, laboratorios, medios de trasporte, maquinas y herramientas, muebles y enseres, Inventarios.

b. Cultura investigativa, logística, marcas, good will. 


\section{INTERACCIÓN CON EL MEDIO}

En las últimas generaciones el hombre civilizado con su presencia y el uso de productos tecnológicos ha venido contaminando el medio ambiente. La responsabilidad social de la empresa con el entorno es cada día mayor, hoy en día se habla de campañas de descontaminación del medio ambiente, del impacto de la empresa en el entorno y que algunos expertos tratan de medir a través de un instrumento que han denominado Balance Social. Debido a lo enunciado anteriormente, hemos tratado de establecer algunos elementos del diseño etnográfico en la empresa que tengan que ver con la interacción con el medio y estos son: impacto ambiental, responsabilidad social, influencia social, identificación de las necesidades de las etnias, campañas de descontaminación del medio ambiente: visual, contra el ruido, protección a la capa de ozono, protección de cuencas hidrográficas, del subsuelo, de la capa vegetal, de la fauna, de ecología humana, de la flora, de salud, de educación a comunidades entre otras. Como también mejoramiento de la calidad de vida de los trabajadores de la empresa, generación de empleo en la región, manejo de riesgos, balance social, auditoria social, ornato y embellecimiento del entorno, Imagen Corporativa y reculturalización de las comunidades que han sido afectadas por las tecnologías del hombre civilizado, este elemento debe considerarse como un volver a la cultura de sus ancestros, a sus raíces.

Hoy los gobiernos se preocupan cada día más por el impacto ambiental y es así como a través de las leyes, normas y reglamentaciones se legisla sobre el particular, por esta razón proponemos esta otra característica en el diseño etnográfico.

\section{ÚLTIMA REFLEXIÓN}

El diseño etnográfico en la empresa debe ser claro, eficaz y minucioso, refiriéndonos al concepto de etnografía como la descripción detallada de una cultura o etnia. "Etimológicamente, el término etnografía significa la descripción (grafé) del estilo de vida de un grupo de personas habituales a vivir juntos (etnos). Por lo tanto, el "etnos" sería la unidad de análisis por el investigador, pudiendo ser una nación, un grupo lingüístico, una región o una comunidad, como también cualquier grupo humano que constituya una entidad cuyas relaciones estén reguladas por la costumbre o por ciertos derechos y obligaciones recíprocos. Así, en la sociedad moderna, una familia, una institución educativa (escuela, colegio, universidad), un aula de clase, una fábrica, una empresa, una cárcel, un gremio obrero, un club social, etc.; son unidades sociales que pueden ser estudiados etnográficamente. Y, en sentido amplio, también son objeto de estudio etnográfico aquellos grupos sociales que, aunque no estén asociados o integrados, comparten o se guían por formas de vida y situaciones que los hacen semejantes, como los alcohólicos, los drogadictos, los delincuentes, los homosexuales, las meretrices, los indigentes, etc.” Martínez, 2001. 
Según Aguirre Baztán en su libro ETNOGRAFÍA, Metodología cualitativa en la investigación sociocultural, define a la empresa, desde su perspectiva de psicólogo cultural, "como una comunidad cultural urbana" y aclara que en su libro Patios abiertos, patios cerrados (1995) clasifica a las comunidades así: patios cerrados (secta, cuartel, cárcel, etc.), patios abiertos (la escuela, hospital, la empresa, el ayuntamiento etc.) En los primeros clausurados sobre sí mismos, se recela del exterior, al que se le da la espalda por medio de muros, alambradas, foros, garitas etc. Por el contrario, en los segundos (patios abiertos) como la empresa, las organizaciones necesitan del exterior, del cliente, son instituciones basadas en la interacción social y cultural. La empresa, es pues, una cultura abierta".

Los miembros de una comunidad, de una cultura o de una etnia comparten una estructura social o de razonamiento y que por lo general no es muy visible pero que se manifiesta en sus actitudes o comportamientos.

El resultado inmediato de un trabajo investigativo etnográfico es crear una imagen clara, realista y fiel de la comunidad objeto de estudio, pero su intención va más allá del retrato del momento en el tiempo, pues analiza, compara, relaciona, interpreta situaciones vividas de las culturas o grupos sociales que investiga.

El objeto de estudio de una investigación etnográfica, según Martínez (2001), "sería la nueva realidad que emerge de la interacción de las partes constituyentes, sería la búsqueda de esa estructura con su función y significado". Esa realidad no está en los elementos sino que aparece por las relaciones que se dan entre ellos por su propia interacción.

Por esta razón al diseñar un modelo etnográfico conviene distinguir claramente este diseño del proyecto de investigación que se presenta para la obtención de recursos. El diseño debe hacerse de acuerdo al tipo y tamaño de empresa que se desee investigar. No es lo mismo, presentar un diseño etnográfico para una fábrica de calzado de un microempresario que el diseño para una institución universitaria. El modelo que se anexa trata de generalizar un poco, sin embargo se pueden sacar de él, elementos particulares para cada empresa.

Con estos aportes al modelo de diseño etnográfico esperamos haber contribuido a la investigación cualitativa, de por sí, fascinante, apasionante y productiva; porque al hombre debe estudiársele como un ser social, integral y complejo que interactúa y se relaciona continuamente con el medio, con otras individuos, especies y en el tiempo. 


\section{REFERENCIAS BIBLIOGRÁFICAS}

- Aguirre, Baztán A. Etnografía. Metodología cualitativa en la investigación sociocultural. Editorial Alfa omega. México, 1997.

- Andrade, H. "Hacia una definición de la cultura organizacional”, en Fernández, C. (comp.) La comunicación en las organizaciones. Editorial Trillas, México, 1996, Cáp.2.

- Cerda G., Hugo. La Investigación Total. Cooperativa Editorial del Magisterio. Bogotá D.C., Colombia 1994.

- Córdova, Víctor. Técnicas Cualitativas de Investigación Social, 1998.

- Drucker P. El Management. Escritos Fundamentales- Argentina: Editorial Suramericana, 202.

- González, M. Olivares S. Comportamiento Organizacional, un enfoque latinoamericano. CECSA. 1999.

- Hellerieg, Slocum y Woodman. Comportamiento Organizacional, Octava Edición. México: International Yhomson Editores S.A. 1998.

- Lerma, Héctor Daniel. Metodología de la Investigación. Bogotá D.C., Colombia, Julio 2001.

- Maldonado, Jorge Enrique. Orientaciones Metodológicas de Investigación. Cúcuta: Editorial Impresión Color, 2011.

- Mártinez, M. La Investigación Cualitativa Etnográfica. Editorial Círculo de Lectura Alternativa Limitada. Bogotá D.C., Colombia, marzo 2001.

- Méndez A., Carlos Eduardo. (2001). Metodología, Diseño y desarrollo de procesos de investigación. Editorial Mc. Graw Hill. Colombia.

- Much, L. y Ángeles, E. (2001). Métodos y Técnicas de Investigación. Editorial Trillas. México.

- Sandoval C., Carlos A. Investigación Cualitativa. Corcas Editores Limitada. Bogotá D.C., Colombia, 1997.

- Tezanos, Araceli de, Una Etnografía de la Etnografía, Ediciones Átropos Limitada. Bogotá D.C., Colombia, 1998. 
Anexo: Cuadro de: Elementos del Diseño Etnográfico en la Empresa.

\begin{tabular}{|c|c|c|c|c|c|}
\hline $\begin{array}{c}\text { CULTURA } \\
\text { ORGANIZACIONAL }\end{array}$ & $\begin{array}{c}\text { COMUNICACIONES } \\
\text { INTERNA- } \\
\text { EXTERNA } \\
\end{array}$ & $\begin{array}{l}\text { PROCESO- } \\
\text { PRODUCTO- } \\
\text { VENTA }\end{array}$ & ESTRATEGIAS & RECURSOS & $\begin{array}{l}\text { INTERACCIÓN } \\
\text { CON EL MEDIO }\end{array}$ \\
\hline Principios & $\begin{array}{l}\text { Formas de } \\
\text { lenguaje }\end{array}$ & $\begin{array}{l}\text { Diagramas de } \\
\text { procesos }\end{array}$ & Planes & $\begin{array}{l}\text { Accesibilidad a } \\
\text { créditos }\end{array}$ & $\begin{array}{l}\text { Impacto } \\
\text { ambiental }\end{array}$ \\
\hline Valores & $\begin{array}{l}\text { Los memorandos y } \\
\text { circulares }\end{array}$ & Innovación & $\begin{array}{l}\text { Desarrollo } \\
\text { humano }\end{array}$ & $\begin{array}{l}\text { Disponibilidad } \\
\text { de Capital }\end{array}$ & $\begin{array}{l}\text { Responsabilidad } \\
\text { social }\end{array}$ \\
\hline Visión & $\begin{array}{l}\text { Los colores, } \\
\text { pinturas }\end{array}$ & Creatividad & Actitud de cambio & $\begin{array}{l}\text { Recursos } \\
\text { presupuéstales }\end{array}$ & Influencia social \\
\hline Misión & $\begin{array}{l}\text { Imágenes } \\
\text { iconográficas }\end{array}$ & Calidad Total & Perspectivismo & $\begin{array}{l}\text { Recursos de } \\
\text { Inversión }\end{array}$ & $\begin{array}{l}\text { Identificación de } \\
\text { necesidades de las } \\
\text { etnias }\end{array}$ \\
\hline Creencias & Canciones & $\begin{array}{l}\text { Manejo } \\
\text { adecuado de } \\
\text { Inventarios } \\
\end{array}$ & Intencionalidad & $\begin{array}{l}\text { Manejo del } \\
\text { riesgo }\end{array}$ & $\begin{array}{l}\text { Descontaminación } \\
\text { del medio } \\
\text { ambiente }\end{array}$ \\
\hline Costumbres & $\begin{array}{l}\text { Comunicación } \\
\text { verbal }\end{array}$ & $\begin{array}{l}\text { Técnicas de } \\
\text { almacenamiento }\end{array}$ & $\begin{array}{l}\text { Nuevos } \\
\text { desarrollos }\end{array}$ & Trabajo Social & $\begin{array}{l}\text { Campañas contra } \\
\text { el ruido }\end{array}$ \\
\hline Normas y reglas & $\begin{array}{l}\text { Comunicación no } \\
\text { verbal, gestos... }\end{array}$ & $\begin{array}{l}\text { Procesos de } \\
\text { reciclaje }\end{array}$ & Desintermediación & $\begin{array}{l}\text { Cultura } \\
\text { investigativa }\end{array}$ & $\begin{array}{l}\text { Campañas de } \\
\text { educación a } \\
\text { comunidades }\end{array}$ \\
\hline Mitos & Logotipo & $\begin{array}{l}\text { Canales } \\
\text { distribución }\end{array}$ & Competitividad & Capital humano & $\begin{array}{l}\text { Descontaminación } \\
\text { visual }\end{array}$ \\
\hline Relatos, Leyendas & Logosímbolos & $\begin{array}{l}\text { Panel de } \\
\text { consumidores }\end{array}$ & Flexibilidad & $\begin{array}{l}\text { Bienestar } \\
\text { institucional }\end{array}$ & $\begin{array}{l}\text { Mejoramiento } \\
\text { calidad de vida } \\
\text { trabajadores }\end{array}$ \\
\hline Historias & Marca de fábrica & $\begin{array}{l}\text { Costeo de } \\
\text { productos }\end{array}$ & Apertura & Planta física & $\begin{array}{l}\text { Generación de } \\
\text { empleo }\end{array}$ \\
\hline Biografías & Nombre producto & Seguros & Rentabilidad & Localización & Manejo de riesgos \\
\hline Ritos & Marca registrada & Know-how & Participación & Redes & Balance Social \\
\hline Proyectos & $\begin{array}{l}\text { Imagen } \\
\text { corporativa }\end{array}$ & Ferias & Anticipación & $\begin{array}{l}\text { Accesibilidad a } \\
\text { Materias Primas }\end{array}$ & $\begin{array}{l}\text { Protección al } \\
\text { medio ambiente }\end{array}$ \\
\hline Capacitación & Publicidad & Cupones & Supervivencia & Dividendos & $\begin{array}{l}\text { Imagen } \\
\text { corporativa }\end{array}$ \\
\hline Deportes & Propaganda & $\begin{array}{l}\text { Despachos } \\
\text { oportunos }\end{array}$ & Descreme de Mdo & Puntos de venta & $\begin{array}{l}\text { Gestión } \\
\text { empresarial }\end{array}$ \\
\hline Selección & Promoción & $\begin{array}{l}\text { Registro de } \\
\text { patentes }\end{array}$ & Adaptabilidad & Logística & Bienestar Social \\
\hline Aprendizaje & Los slogan & Otros servicios & Globalización & Almacenamiento & $\begin{array}{l}\text { Campañas de } \\
\text { Salud }\end{array}$ \\
\hline Socialización & Los jingles & Benchmarking & Credibilidad & Laboratorios & Retroalimentación \\
\hline $\begin{array}{l}\text { Relaciones } \\
\text { formales }\end{array}$ & Las trovas & $\begin{array}{l}\text { Código de } \\
\text { barras }\end{array}$ & $\begin{array}{l}\text { Mejoramiento } \\
\text { continuo }\end{array}$ & $\begin{array}{l}\text { Optimización de } \\
\text { proveedores }\end{array}$ & $\begin{array}{l}\text { Protección de } \\
\text { cuencas } \\
\text { hidrográficas }\end{array}$ \\
\hline Comportamientos & Los himnos & $\begin{array}{l}\text { Organización - } \\
\text { venta }\end{array}$ & Penetración & De distribución & $\begin{array}{l}\text { Protección capa } \\
\text { de ozono }\end{array}$ \\
\hline $\begin{array}{l}\text { Relaciones } \\
\text { informales }\end{array}$ & $\begin{array}{l}\text { La bandera, el } \\
\text { escudo }\end{array}$ & $\begin{array}{l}\text { Sistemas de } \\
\text { transporte }\end{array}$ & $\begin{array}{l}\text { Respuesta } \\
\text { oportuna }\end{array}$ & $\begin{array}{l}\text { Medios de } \\
\text { transporte }\end{array}$ & $\begin{array}{l}\text { Protección del } \\
\text { subsuelo }\end{array}$ \\
\hline $\begin{array}{l}\text { Identidad y } \\
\text { Pertenencia }\end{array}$ & $\begin{array}{l}\text { Sistemas de } \\
\text { Información }\end{array}$ & $\begin{array}{l}\text { Niveles de } \\
\text { satisfacción }\end{array}$ & $\begin{array}{l}\text { Manejo de } \\
\text { prioridades }\end{array}$ & $\begin{array}{l}\text { Infraestructura } \\
\text { tecnológica }\end{array}$ & $\begin{array}{l}\text { Protección de la } \\
\text { capa vegetal }\end{array}$ \\
\hline
\end{tabular}




\begin{tabular}{|l|l|l|l|l|l|}
\hline & & clientes & & \\
\hline $\begin{array}{l}\text { Anhelos, } \\
\text { aspiraciones }\end{array}$ & $\begin{array}{l}\text { Atención al } \\
\text { teléfono }\end{array}$ & $\begin{array}{l}\text { Portafolio de } \\
\text { Productos }\end{array}$ & $\begin{array}{l}\text { Alianzas } \\
\text { estratégicas }\end{array}$ & Equipos & $\begin{array}{l}\text { Protección de la } \\
\text { fauna }\end{array}$ \\
\hline $\begin{array}{l}\text { Emociones, } \\
\text { sentimientos }\end{array}$ & $\begin{array}{l}\text { Atención a } \\
\text { reclamación de } \\
\text { clientes }\end{array}$ & $\begin{array}{l}\text { Exportación de } \\
\text { productos y } \\
\text { servicios }\end{array}$ & $\begin{array}{l}\text { Crecimiento de } \\
\text { Infraestructura }\end{array}$ & $\begin{array}{l}\text { Máquinas y } \\
\text { Herramientas }\end{array}$ & $\begin{array}{l}\text { Programas de } \\
\text { Ecología Humana }\end{array}$ \\
\hline $\begin{array}{l}\text { Religión y } \\
\text { Espiritualidad }\end{array}$ & $\begin{array}{l}\text { Relaciones } \\
\text { Públicas }\end{array}$ & $\begin{array}{l}\text { Adopción de } \\
\text { nuevos } \\
\text { conocimientos }\end{array}$ & $\begin{array}{l}\text { Administración } \\
\text { del caos }\end{array}$ & $\begin{array}{l}\text { Muebles y } \\
\text { Enseres }\end{array}$ & $\begin{array}{l}\text { Protección de la } \\
\text { flora }\end{array}$ \\
\hline $\begin{array}{l}\text { Formación } \\
\text { Tecnológica }\end{array}$ & Versos y poemas & $\begin{array}{l}\text { Donaciones de } \\
\text { productos }\end{array}$ & Masificación & Inventarios & Auditoria Social \\
\hline $\begin{array}{l}\text { Clima } \\
\text { Organizacional }\end{array}$ & $\begin{array}{l}\text { Empliación y } \\
\text { profundidad de } \\
\text { producción }\end{array}$ & $\begin{array}{l}\text { Línea de } \\
\text { productos }\end{array}$ & Evaluación de la \\
competencia & Good-will & $\begin{array}{l}\text { Ornato y } \\
\text { embellecimiento } \\
\text { del entorno }\end{array}$ \\
\hline $\begin{array}{l}\text { Estilos de } \\
\text { Liderazgo }\end{array}$ & Rumores \\
\hline $\begin{array}{l}\text { Fuente: Adaptación al modelo del Diseño Etnográfico de la empresa de Aguirre Baztán por: Jorge Enrique } \\
\text { Maldonado Pinto. }\end{array}$ & Degustaciones & Creación de Valor & Propiedades & $\begin{array}{l}\text { Reculturalización } \\
\text { de comunidades }\end{array}$ \\
\hline
\end{tabular}

